\title{
How Customer Affect Agile Transition and Adoption Process?
}

\author{
[Taghi Javdani Gandomani, Mina Ziaei Nafchi]
}

\begin{abstract}
Software teams and companies are continually leaving plan driven methods and replacing them by Agile methods in software development. One of the most important reasons for this process is gaining more quality in software products. This process as a multi-dimensional process encompasses several factors, enablers, challenges, and obstacles. Conducting a large scale qualitative research study revealed various hidden aspects of the above process. This paper presents the role of customers as one of the most critical roles in Agile transition and adoption. This study showed that customers significantly influence the change process and can be considered as both successful and failure factors in the transformation.
\end{abstract}

Keywords - Agile software development, Agile transition process, Agile transition and adoption, Agile customer, Customer involvement, Grounded Theory

\section{Introduction}

Software market has been dramatically changing in the last decade. Different types of software packages with different platforms and size are requested by different customers. At the same time, software companies try to use the best and most effective development methodologies, methods, and tools to develop better software products and win the competition they are in.

Applying appropriate development methodology can dramatically affect the quality of the software products and improving customer happiness. For more than several decades, software companies have used disciplined-based/ plan-driven methodologies, known as traditional methods, in their production lines. However, many challenges and problems have been encountered while using these methodologies. Customers' dissatisfaction, late delivery, cost overrun, heavy documentation, etc. are the most important challenges of using traditional methods [1]. Agile methods as a reaction to problems of the traditional methods have been introduced in 2001 [2]. These methods accentuate the values which are against the traditional methods [3].

Leaving plan-driven methods and adopting Agile methods is known as Agile transformation/ transition and adoption process. This process is more difficult than it appears. Indeed, there are many challenges and obstacles that software teams and companies face with when they are altering their development methodologies $[4,5]$.

Taghi Javdani Gandomani, Mina Ziaei Nafchi Computer Dept. Boroujen Branch, Islamic Azad University, Boroujen, Iran
Agile transformation is a multi-dimensional process in which various factors interconnect to achieve the goals of change process. This process as a people-centric process, is strongly affected by involved people [6]. The involved people need to change their traditional roles and responsibilities and adapt them to what Agile expects.

Compared to the traditional methods, customers play a more critical role in Agile methods. Most of the Agile methods consider customer as a member of development team $[7,8]$. This approach identified the importance role of customer in Agile transformation. However, if customers are not ready or do not willing to collaborate in the change process, Agile transformation would be difficult or sometimes impossible [4].

This paper intends to express the significant role of customers in Agile transformation process. Conducting a large scale Grounded Theory study helped to explore role of customer in adapting to Agile methods generally, and Agile transition and adoption process particularly.

This paper is organized as the follows. Next section explains the previous works, continued by a short explanation about the adopted research methodology. After that, the results will be presented. Finally, the paper will be concluded.

\section{Previous Studies}

Role of customer in Agile software development has been studied in a few research studies. However, none of them has been focused on Agile transition process. Indeed, most the previous studies have focused on the role of customer in a specific Agile method or a particular concept of Agile approach.

Martin, et al. [9] explained that though customers and developers need to collaborate effectively in Agile software development generally and XP method particularly, only a few practices have been dedicated to them. She emphasized that although customers and developers are working together in XP, they have not the same attitude or behaviors; developers are from Mars, customers are from Venus! [9]. She, then suggested a number of patterns to cover key roles required on a customer team and practices to enable customers to drive XP successfully [9]. Later, carrying out a qualitative study, role of customers in XP projects has been elaborated [10]. 
In another study, the impact of customer communication on defect of Agile software development has been studied [7]. The scholars by suggesting a set of guidance for selecting appropriate communication methods showed that increased reliance on less informative communication methods will result in higher defect rates. Later, the relationship between developers and customers has been studied in detail [11]. Moreover, this study addressed some probable challenges of working customers and developers together as a team.

[12] studied the role of customers in self-organizing Agile team and showed that lack of adequate customer involvement is a serious challenge in such teams. They also demonstrated the consequences of lack or insufficient customer collaboration and proposed a set of strategies to cope with its adverse consequences.

In a different empirical study, the researchers investigated the effectiveness of customer collaboration in a case study and showed that although customer involvement was $100 \%$, only $21 \%$ of his effort was required in the current project [13]. They also found that in some cases onsite customer may create a false sense of confidence in the system under development.

In another study customer participation in an Agile company and a traditional company was studied [14]. The result showed that customer collaboration can be helpful in all projects regardless than Agile or traditional development methodologies. This study also showed that higher customer participation leads to higher customer satisfaction.

\section{Research Methodology}

This study has adopted Grounded Theory (GT) [15]. GT as a qualitative research methodology tries to inductively develop a grounded theory to represent a reality under study. GT suggests a systematic approach to collect data, analysis them, and eventually generating a theory. This method is so helpful to answer questions like "what is going on in an area?" [16]. This study started with a minor literature review to avoid the researchers' biases influencing the answers. The steps and activities of the employed research methodology have been elaborated in detail in $[17,18]$. This study carried out with the participation of 49 Agile experts from 13 different countries. They had various jobs and responsibilities in Agile teams including Agile developers, Agile coaches, Agile consultants, Scrum masters, Project managers, etc.

\section{Results}

This study aimed to find the all aspects of transformation to Agile and their related realities [19]. Data analysis showed that the transition process is strongly influenced by customers. Figure 1 showed the category of customers related issues in Agile transition process. Figure 1 shows the customers' related issues resulted in data analysis phase.

The rest of this section briefly presents the emerged concepts. Though GT papers support their findings with participants' quotations, this paper avoid the quotations because of space limitation.

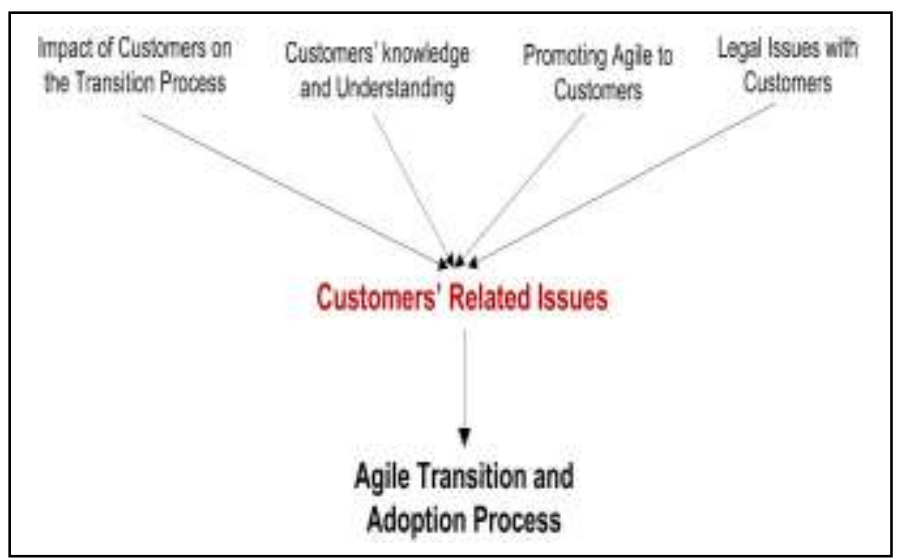

Figure 1. Exploring customers' related issues from underlying concepts

\section{A. The Impact of Customers on Agile Transformation Process}

Data analysis showed that customers' involvement and participation has a significant impacts on the transition process. Agile methods have defined many particular practices for customers during the software development process. Therefore, adapting to Agile methods strongly needs to customers collaboration. The participant declared that without customers' collaboration the change process has a little chance to success. This is more critical when adopting XP and Scrum. This is mainly because these methods have defined serious customers' practices.

\section{B. Customers' Knowledge and Understanding}

The participants explained that lack of customers' knowledge and understanding about Agile software development and transformation process is a serious barrier in Agile adoption. They declared that this issue leads to insufficient participation and collaboration. They added that customers need to learn their new roles and responsibilities. Providing a training package for customers was a serious suggestion provided by the research participants. They believed that Agile coaches need to consider proper training materials to teach customers (along with technical team) before starting initial Agile project (pilot project). Generally, the participants complain about finding supportive Product Owner (PO).

\section{Promoting Agile to Customers}

The participants emphasized that customers need a convincing reason to accept collaboration with Agile teams. They added that increasing their knowledge about Agile advantages and promoting Agile values would be helpful in this matter. They believed that promoting Agile values directly leads to customers' involvement and participation. The participants also stressed that providing early business benefits would be the best promotion strategy for collaboration of all development team members including customers. 


\section{Legal Issues with Customers}

Legal issues have been addressed as the last important issue regarding to Agile customers. As the participants declared, most often customers' internal rules are a serious obstacle in adopting Agile methods. For instance, they mentioned that most often customers persist on fixed-price, fixed-scope contracts. This challenge is more serious in public sectors. Obviously, Agile project is better to be negotiable in terms of budget and scope. Furthermore, some of the participants declared that some of their customers cannot collaborate as an on-site full-time team member due to their internal laws.

\section{CONCLUSION}

This study investigated Agile transformation process to explore its various dimensions and aspects. Adopting a Grounded Theory with participation of 49 Agile experts revealed almost all import issues regarding to Agile transition and adoption process in which customers' related issues have been addressed as a serious aspect.

Data analysis showed that this change process is strongly influenced by customers' collaboration and participation. Indeed, Agile transformation without sufficient customer involvement would be doomed to failure. Also, customers' knowledge and understanding about Agile software development is a critical issue in Agile transformation. Data analysis showed that most often customers have not sufficient knowledge regarding to their new roles and this leads to serious challenges in the transition process. Also, promoting Agile and its promised values is necessary to engage customers to collaborate in the change process. The last issue was legal limitations in customers' companies which act as a serious barrier in Agile transition process. For instance, most often customers from public sector need to have a fixed-price and fixed-scope contract which is not a good condition in Agile software development.

\section{Acknowledgment}

The authors would like to thank all the participants in this study. This study was partially founded by Univeriti Putra Malaysia (UPM), Malaysia and Islamic Azad University, Boroujen Branch, Boroujen, Iran.

\section{References} K. Conboy, S. Coyle, X. Wang, and M. Pikkarainen, "People
over process: Key challenges in agile development," IEEE

Software, vol. 28, pp. 48-57, 2011.
A. Cockburn and J. Highsmith, "Agile software development: The people factor," Computer, vol. 34, pp. 131-133, 2001.

M. Korkala, P. Abrahamsson, and P. Kyllönen, "A case study on the impact of customer communication on defects in Agile software development," Minneapolis, MN, 2006, pp. 76-86.

K. Conboy and L. Morgan, "Beyond the customer: Opening the agile systems development process," Information and Software Technology, vol. 53, pp. 535-542, 2011.

A. Martin, J. Noble, and R. Biddle, "Programmers are from Mars, customers are from Venus: A practical guide for customers on XP projects," Portland, OR, 2006.

A. Martin, R. Biddle, and J. Noble, "The XP customer team: A grounded theory," in Agile Conference, Chicago, IL, 2009, pp. 57-64.

W. Xiaohua, W. Zhi, and Z. Ming, "The relationship between developers and customers in agile methodology," Singapore, 2008, pp. 566-572.

R. Hoda, J. Noble, and S. Marshall, "The impact of inadequate customer collaboration on self-organizing Agile teams," Information and Software Technology, vol. 53, pp. 521-534, 2011.

J. Koskela and P. Abrahamsson, "On-Site customer in an XP Project: Empirical results from a case study," vol. 3281, ed, 2004, pp. 1-11.

Z. Racheva and M. Daneva, "Clients' participation in software projects: comparative case study between an agile and a "traditional'software company," 2010.

B. Glaser and A. Strauss, The Discovery of Grounded Theory: Strategies for Qualitative Research. Chicago: Aldine Transaction, 1967.

J. M. Corbin and A. C. Strauss, Basics of Qualitative Research: Techniques and Procedures for Developing Grounded Theory (3e). Thousand Oaks, California: SAGE Publications Inc., 2008. T. J. Gandomani, H. Zulzalil, A. A. A. Ghani, A. B. M. Sultan, and R. M. Parizi, "The impact of inadequate and dysfunctional training on Agile transformation process: a Grounded Theory study," Information and Software Technology, vol. 57, pp. 295309, 2015.

T. J. Gandomani, h. Zulzalil, A. A. A. Ghani, A. B. M. Sultan, and K. Y. Sharif, "How Grounded Theory can facilitate research studies in context of Agile software development," Science International-Lahore, vol. 25, pp. 1131-1136, 2013.

T. J. Gandomani, H. Zulzalil, and M. Z. Nafchi, "Agile Transformation: What is it about?," in 8th Malaysian Software Engineering Conference (MySEC), Langkawi, Malaysia, 2014, pp. 240-245. 